\title{
Pola Memusat: Salah Satu Model Kosmologis Pada Masa Prasejarah Di Indonesia
}

\section{Sunarningsih}

Keywords: cosmology, pattern, model, development, hindu-buddha, prehistory

\section{How to Cite:}

Sunarningsih, nfn. (1999). Pola Memusat: Salah Satu Model Kosmologis Pada Masa Prasejarah Di Indonesia. Berkala Arkeologi, 19(2), 30-38. https://doi.org/10.30883/jba.v19i2.821

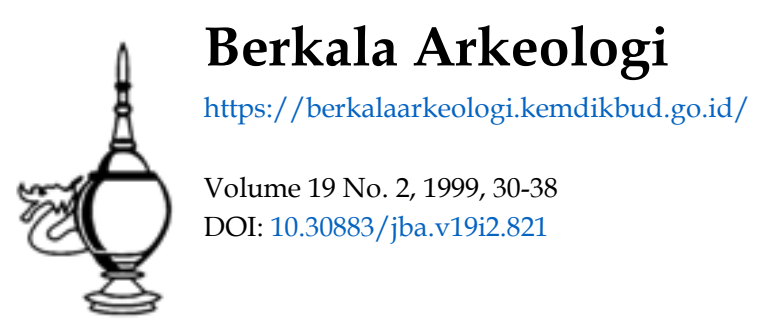

\section{c) (†) (ㅇ)}

This work is licensed under a Creative Commons Attribution-NonCommercial-ShareAlike 4.0 International License. 


\title{
POLA MEMUSAT: SALAH SATU MODEL KOSMOLOGIS PADA MASA PRASEJARAH DI INDONESIA*
}

\author{
Sunarningsih \\ (Balai Arkeologi Irian Jaya)
}

Masa Prasejarah adalah masa di mana manusia belum mengenal tulisan. Para ahli mempelajari kehidupan manusia pada masa prasejarah ini hanya berdasar pada bendabenda yang ditinggalkan oleh manusia pada masa itu, tanpa bantuan kitab-kitab tertulis atau peninggalan yang berupa tulisan lainnya.

Perubahan kebudayaan manusia antara lain disebabkan karena perubahan lingkungan, karena semata-mata kebetulan, dan kontak dengan kebudayaan lain (Haviland, 1988). Proses atau mekanisme yang terlibat dalam perubahan kebudayaan adalah penemuan baru (invention), difusi, hilangnya unsur kebudayaan dan akulturasi (Ibid). Penemuan baru (invention) mengacu pada penemuan cara kerja, alat atau prinsip baru oleh individu yang kemudian menjadi milik masyarakat. Penemuan itu sendiri terbagi menjadi penemuan yang bersifat primer dan sekunder. Penemuan primer adalah adalah penemuan secara kebetulan suatu prinsip baru, sedangkan penemuan sekunder adalah perbaikan-perbaikan yang diadakan dengan menerapkan prinsip-prinsip yang sudah diketahui (Ibid.). Dengan adanya penemuan sekunder tersebut kebudayaan mengalami perkembangan.

Salah satu hasil kebudayaan (konsep) yang mengalami perkembangan dari masa prasejarah ke masa pengaruh Hindu, bahkan sampai masa pengaruh Islam adalah kepercayaan masyarakat terhadap keberadaan gunung. Masyarakat prasejarah mempunyai kepercayaan bahwa tempat tinggal arwah nenek moyang adalah pada puncak-puncak gunung atau bukit (Wales, 1958). Selanjutnya masyarakat Hindu juga mempercayai bahwa puncak Gunung Meru merupakan tempat kota dewa-dewa (Geldern, 1982).

Keberadaan Gunung Meru tersebut berhubungan dengan satu konsep tentang pembentukan dunia yang disebut dengan konsep kosmologi. Para ahli menghubungkan konsep tersebut dengan latar belakang pendirian kerajaan dan candicandi masa Hindu yang berpola konsentris. Pada candi-candi di Indonesia yang

\footnotetext{
- Pernah dipresentasikan pada Seminar Prasejarah Indonesia I, 1-3 Agustus 1996, dengan sedikit perubahan.
} 
muncul pada masa akhir Majapahit, yang mempunyai pola memusat ke belakang (seperti punden berundak) dikatakan telah mengalami perubahan orientasi, yaitu dari kosmis (mata angin) ke ktonis (gunung) (Tjahjono, 1992).

Konsep kosmologis menurut Doktrin Brahma, yaitu jagad raya terdiri atas sebuah benua berbentuk lingkaran dan terletak di pusat, dikelilingi oleh tujuh buah samudra berbentuk cincin dan tujuh benua berbentuk cincin pula. Di luar samudra terakhir, jagad ditutupi oleh barisan pegunungan yang sangat besar. Di tengah-tengah jagad berdirilah Gunung Meru sebagai kosmis yang diedari oleh matahari, bulan, dan bintang. Di puncak Gunung Meru terletak kota-kota dewa yang dikelilingi oleh tempat tinggal dari delapan lokapala atau dewa penjaga (Geldern, 1982).

Robert von Heine Geldern dalam bukunya yang berjudul Konsepsi tentang Negara dan Kedudukan Raja di Asia Tenggara, menyatakan bahwa bentuk-bentuk kerajaan di Asia Tenggara yang memiliki pola memusat merupakan salah satu penggambaran kosmologi. Kerajaan masa Hindu , di Asia Tenggara tersebut dibangun sebagai penggambaran kosmis yang dianggap sebagai replika kosmos, sehingga terdapat kesejajaran antara kerajaan dan dunia. Geldern juga menyebutkan bahwa pola-pola candi masa Hindu di Asia Tenggara juga menggunakan model kosmologis tersebut.

Dalam tulisannya tersebut Geldern melupakan satu hal, yaitu bahwa pola kerajaan dan candi-candi di Asia Tenggara memang merupakan bangunan yang memusat (konsentris). Akan tetapi, bangunan-bangunan tersebut tidaklah berbentuk lingkaran konsentris sesuai dengan konsepsi kosmologi dalam doktrin Brahma, tetapi berbentuk persegi konsentris. Oleh karena itu, apabila bentuk kota dianggap replika dunia terdapat ketidaksesuaian (Tanudirjo, 1985).

Bentuk-bentuk persegi konsentris tersebut sebenarnya telah ada sejak masa prasejarah. Bisa dikatakan bahwa bentuk-bentuk model kosmologis pada masa Hindu tersebut hanyalah pakaian baru untuk tubuh yang lama (Ibid.). Konsepsi kosmologis dan inti alam pikiran tersebut telah ada jauh sebelum kedatangan Hindu. William Alkire, seorang ahli antropologi mengemukakan, bahwa orang-orang Austronesia telah mempunyai konsepsi kosmologis dunia berbentuk persegi ketika mereka belum menyebar ke berbagai tempat. Gagasan tersebut didasarkan pada keahlian ilmu astronomi mereka (Ibid.). 
Bangunan berbentuk persegi konsentris yang ditemukan pada masa prasejarah di Indonesia adalah punden berundak. Bangunan punden berundak tersebut juga ditemukan di luar wilayah Indonesia (Asia Pasifik). Bangunan berundak yang ditemukan di Indonesia, antara lain di daerah Jawa Tengah, Jawa Barat, dan Lampung. Punden berundak yang didapatkan di Indonesia pada umumnya memiliki dua bentuk denah poko, yaitu berdenah konsentris (memusat ke tengah) dengan undak-undakannya yang semakin ke atas semakin mengecil membentuk piramida dan berdenah memusat ke belakang, yaitu undak-undakannya semakin meninggi ke belakang (Susatyo, 1993) (lihat gb. 1).

Bangunan berundak di daerah Jawa Barat, yaitu punden berundak Lebak Cibedug, Arca Domas, Pangguyangan, dan Kosala memiliki bentuk denah konsentris. Satusatunya punden berundak di Jawa Barat yang memiliki bentuk denah memanjang ke belakang adalah punden berundak Gunung Padang (Ibid.). Bangunan berundak Pugungraharjo, Lampung mempunyai denah konsentris, sedangkan punden berundak di daerah Cilongok, Jawa Tengah semuanya berdenah memusat ke belakang (Ibid., hlm. 64-74). Baskoro D. Tjahjono dalam artikelnya yang berjudul "Gejala Perubahan Orientasi Kosmis ke Ktonis pada Arsitektur Bangunan Sakral Majapahit Akhir" menyimpulkan, bahwa pembangunan candi mulai abad XIV M tidak lagi berorientasi ke kosmis (arah mata angin), tetapi ke ktonis (alam). Hal tersebut tampak antara lain pada Candi Sukuh, Candi Penataran, dan candi-candi di Gunung Penanggungan yang tidak lagi berdenah konsentris, tetapi memusat ke belakang seperti halnya bangunan punden berundak. Jadi bangunan candi yang berpola memusat ke belakang tersebut tidak lagi merupakan perwujudan dari replika kosmos. Di Candi Sukuh (bangunan paling belakang) terdapat bentuk naga (pada puncak lubang pintu, berjumlah empat saling berkaitan dan kira-kira di depan pintu masuk, juga berjumlah empat buah) yang melambangkan cerita samudramanthana. Jelas terlihat bahwa sebenamya candi pusat tersebut dianggap sebagai gunung yang dililit oleh naga dengan kura-kura sebagai alasnya (seperti cerita dalam proses pembentukan dunia). Cerita tersebut, juga ditemukan pada Candi Penataran. Berpijak pada kenyataan tersebut muuncul pertanyaan, apakah benar candi-candi yang berpola memusat ke belakang tersebut bukan lagi merupakan replika dari kosmos?

Kembali pada bentuk bangunan berundak, ternyata punden berundak di daerah Jawa Barat dipengaruhi oleh kondisi lingkungannya. Hal tersebut dapat dibuktikan oleh Doni Sugio Budi Susatyo dalam skripsinya yang berjudul "Punden Berundak di Jawa Barat Tinjauan Atas Bentuk Denah". Pembangunan punden berundak yang memiliki denah konsentris dan memusat ke belakang disesuaikan dengan kondisi tempat punden berundak tersebut didirikan. Bangunan berundak yang berdenah konsentris didirikan pada tempat yang datar, yang kemudian dibuat bertingkat-tingkat, semakin ke atas semakin kecil. Bangunan tersebut berada pada sebuah bukit, sehingga tinggal menyesuaikan dengan bentuk bukit tersebut. Adapun bangunan berundak yang 
memusat ke belakang, didirikan pada lereng sebuah gunung yang tidak memungkinkan untuk dibuat sebuah bangunan konsentris. Bangunan-bangunan berundak tersebut, baik yang berdenah konsentris maupun memanjang ke belakang (memusat ke belakang) merupakan replika sebuah gunung yang dianggap sebagai tempat bersemayamya arwah nenek moyang (Susatyo, 1993)

Persamaan dari kedua jenis denah tersebut, di samping sama-sama merupakan replika dari gunung juga mempunyai satu pusat bangunan yang dianggap paling suci, yaitu yang berada di tengah (denah konsentris) dan yang ada pada bangunan paling belakang (denah memusat ke belakang). Penulis berasumsi bahwa bangunan punden berundak tersebut juga melambangkan dunia atas dan dunia bawah, yang ditunjukkan dengan adanya bangunan paling suci (sakral) dan bagian yang profan. Tidak tertutup kemungkinan, bahwa bentuk persegi tersebut juga mewakili arah-arah tertentu (barat, timur, utara, dan selatan) dan wilayah tengah (center). Hanya saja konsep-konsep masyarakat prasejarah tersebut tidak dituliskan dalam prasasti atau kitab-kitab seperti dalam masa Hindu, sehingga para ahli tidak dapat mengetahui secara pasti. Perlu digarisbawahi bahwa orientasi kosmis muncul karena adanya pemikiran yang dihubungkan dengan alam semesta (kosmos), yaitu bintang, bulan, matahari, samodra, dan gunung. Nampak bahwa dasar model kosmologis yang berkembang di Asia Pasifik tidak terlepas dari kondisi alamnya, yang terdiri atas lautan dan daratan (gunung). Model kosmologis mungkin juga muncul akibat adanya pengalaman dalam proses pergantian daratan dan lautan, serta muncul dan tenggelamnya pulau, atau akibat ledakan gunung berapi (Jumsai, 1988). Dan apabila dilihat lingkungan alam di daerah Asia Pasifik, yang terdiri atas daratan dan lautan, tampak bahwa model-model kosmologis sangat dipengaruhi oleh kondisi alam tersebut.

Berkenaan dengan arah mata angin, pada kubur prasejarah orientasi yang digunakan adalah barat-timur. Namun demikian ada juga yang berorientasi utara-selatan. Araharah tersebut dihubungkan dengan arah terbit dan terbenam matahari, yang menggambarkan kematian dan kehidupan. Di samping itu, juga dihubungkan dengan arah gunung, yang dianggap sebagai tempat arwah nenek moyang. Anggapan terhadap arwah nenek moyang yang berada di seberang lautan, juga ditunjukkan dalam penguburan, yaitu bentuk-bentuk peti kubur batu yang serupa dengan perahu. Kedatangan nenek moyang dari seberang lautan tersebut, juga memberi peluang terhadap arah utara-selatan (Sektiadi, 1999).

\section{III}

Konsepsi kosmologis dalam doktrin Brahma, menyebutkan pula bahwa jagat raya (Jambhudwipa) didukung oleh naga sesa. Cerita tentang pembentukan dunia, yaitu Samudramanthana, menceritakan adanya binatang yang ikut berperan dalam proses 
tersebut, yaitu naga dan kura-kura. Penggambaran cerita tersebut dapat ditemukan pada candi-candi masa Hindu di Indonesia, antara lain Candi Sukuh dan Candi Penataran. Selain di Indonesia, penggambaran binatang naga sebagai simbol kosmologis juga ditemui di wilayah Asia Tenggara lainnya, baik di daratan maupun di kepulauan, yaitu antara lain Thailand dan Cina.

Adanya kepercayaan terhadap binatang sebenamya sudah berkembang jauh sebelum adanya pengaruh Hindu. Tidak ketinggalan pula dua jenis binatang yang berperan dalam proses pembentukan dunia tersebut. Naga telah menjadi binatang yang diyakini memiliki kekuatan tertentu karena binatang tersebut dapat hidup di dua dunia, yaitu darat dan air (amphibi), yang dianggap sebagai simbol air. Pemilihan binatang naga sebagai simnol disebabkan karena bentuk morfologinya yang lurus dan sangat fleksibel untuk digambarkan, antara lain bisa digambarkan sebagai simbol gelombang air laut (berkelok-kelok) dan pusaran air (melingkar/lingkaran konsentris) (Jumsai, 1988).

Pola lingkaran memusat (coil), sudah ditemukan pada masa prasejarah, yaitu antara lain hiasan pada kano di Maori dan pada perahu di kubur prasejarah Philipina (Ibid., $\mathrm{hlm}$. 20). Lalu bagaimanakah penggambaran model kosmologis dengan pola lingkaran memusat pada masa prasejarah di Indonesia, yang diwakili oleh binatang ular?

Berdasarkan hasil penelitian terhadap budaya masa prasejarah di Indonesia, pola-pola hias lingkam memusat banyak ditemukan baik pada lukisan dinding gua, maupun pada batu bergores. Selama ini, hiasan tersebut dianggap sebagai hiasan geometris belaka, mungkin juga mengandung simbol tertentu yang belum dapat dipastikan artinya. Berdasarkan data etnografi masyarakat Suku Asmat Irian Jaya, yang memiliki banyak sekali motif hias, terdapat motif pusar atau mata, yaitu tiga lapisan lingkaran dengan titik hitam di tengahnya. Motif tersebut merupakan lambang lingkaran hidup manusia, dimaksudkan agar semua orang taat kepada norma-norma adat. Pola-pola hias binatang ular juga ditemukan, tetapi untuk binatang naga jarang (tidak ada?).

Salah satu bentuk hiasan yang berupa lingkaran memusat adalah hiasan pada bidang pukul nekara. Seperti telah kita ketahui, bahwa nekara merupakan salah satu benda arkeologis yang ditemukan di wilayah Indonesia dan Asia Tenggara lainnya. Benda tersebut selama ini dianggap sebagai alat musik yang berfungsi dalam upacaraupacara. Hal itu didasarkan pada adanya hiasan katak yang dianggap sebagai simbol binatang air (untuk memanggil hujan). Bentuk bidang pukul nekara tersebut berupa lingkaran dengan bagian tengahnya (pusat) berupa motif bintang yang dibuat menonjol. Menurut Kempers, motif bintang yang dibuat menonjol tersebut dimaksudkan agar suara yang dihasilkan lebih keras. Apakah motif bintang tersebut hanya digunakan semata-mata untuk memperkeras suara yang dihasilkan? Apabila dilihat secara keseluruhan, baik bentuk nekara maupun fungsinya yang sakral, 
tidaklah mengada-ada apabila hiasan-hiasan yang dipilih untuk menghiasi seluruh bagian nekara mewakili simbol-simbol tertentu. Bentuk bagian bidang pukul yang bulat, dengan pola hiasnya yang memusat mungkin terdapat hubungan. Maksudnya adalah terdapat pengaruh antara bentuk bulat tersebut dengan pola hias yang dipilih. Namun, sebenarnya apabila kita pikirkan lebih jauh lagi, bentuk bidang pukul yang bulat tersebut tidaklah harus dihiasi dengan pola-pola yang memusat. Berdasarkan pola pikir semacam itu, muncul pemikiran bahwa bisa jadi pola lingkaran memusat tersebut juga memiliki makna-makna yang ada hubungan dengan konsep kosmologis. Pola bintang pada pusatnya yang dilanjutkan dengan pengisian motif-motif hias lainnya pada pita-pita yang mengelilingi motif binatang, sesuai dengan konsepsi kosmologis, dimana dunia dikelilingi oleh tujuh buah samodra dan tujuh buah benua. Pola hias tersebut umumnya berasal dari nekara yang ditemukan di wilayah Indonesia timur (lihat gambar. 2).

Seperti telah disebutkan di atas, bahwa orientasi kosmis muncul karena adanya pemikiran yang dihubungkan dengan alam semesta (kosmos), yaitu bintang, bulan, matahari, samodra, dan gunung. Motif hias yang ada pada bagian tengah bidang pukul adalah bintang, yang menurut Kempers tidak hanya sekedar bintang saja tetapi sebagai solar star atau matahari. Motif hias yang mengelilingi matahari kebanyakan berupa motif binatang (burung), manusia dengan aktivitasnya, serta motif geometris (meander, spiral, dsb.) (Kempers, 1988). Motif hias tersebut (binatang, manusia, dan rumah) digambarkan dalam arah yang sama, baik searah jarum jam maupun berlawanan dengan jarum jam, seperti bergerak dalam lingkaran tersebut.

Keberadaan motif hias yang mengelilingi matahari sebagai pusatnya menggambarkan kehidupan manusia (dunia bawah), kehidupan burung (dunia atas, dan juga kehidupan di air yang diwakili oleh motif katak, kiranya merupakan simbol dari suatu konsep yang dimiliki oleh masyarakat pendukungnya.

\section{IV}

Berdasarkan uraian di atas, dapat ditarik kesimpulan bahwa pada masa prasejarah di Indonesia sudah dijumpai model kosmologis pada bangunan berundak dan pada pola hias bidang pukul nekara. Bisa dikatakan bahwa pemikiran awal (cikal bakal) konsepsi kosmologis sudah ada sejak masa prasejarah, yang kemudian dikembangkan pada masa Hindu. Dengan kemajuan teknologi yang telah dimiliki dan tambahan pengetahuan dalam konsep tersebut, maka dibangunlah tempat-tempat suci (candi) sebagai replika kosmos dengan lebih megah, bagus, dan lengkap. 


\section{KEPUSTAKAAN}

Geldern, Robert von Heine. 1982. Konsepsi tentang Negara dan Kedudukan Raja di Asia Tenggara. Terjemahan Deliar Noer. Jakarta: Rajawali.

Haviland, William A. 1988. Antropologi Jilid 2. Terjemahan R.G. Soekadijo. Jakarta: Erlangga.

Jumsai, Sumset. 1988. Naga: Cultural Origins in Siam and the West Pacific. Singapore: Oxford University Pres.

Kempers, A.J. Bernet. 1988. The Kettledrums of Southeast Asia. Rotterdam: A.A. Balkema.

Sektiadi. 1999. Utara-Selatan Aspek Dualisme dalam Kajian Arkeologis, Artefak No. 21/Feb. Yogyakarta: Jur. Arkeologi, Fak. Sastra UGM. Hlm. 10-17.

Susatyo, Doni Sugio Budi. 1993. Punden Berundak di Jawa Barat Tinjauan Atas Bentuk Denah, Skripsi Sarjana Arkeologi. Yogyakarta: Fak. Sastra UGM.

Tanudirjo, Daud Aris. 1985. Mempersoalkan Akar Budaya Asia Tenggara, Artefak No. 3/II. Yogyakarta: Jur. Arkeologi, Fak. Sastra UGM. Hlm. 26-28.

Tjahjono, Baskoro Daru. 1992. Gejala Perubahan Orientasi Kosmis ke Ktonis pada Arsitektur Bangunan Sakral Majapahit Akhir, Pertemuan Ilmiah Arkeologi VI. Jakarta: Puslit Arkenas. Hlm. 1-6.

Wales, H.G. Quaritch. 1985. The Mountain of God. London: Bernard Quaritch LTD. 


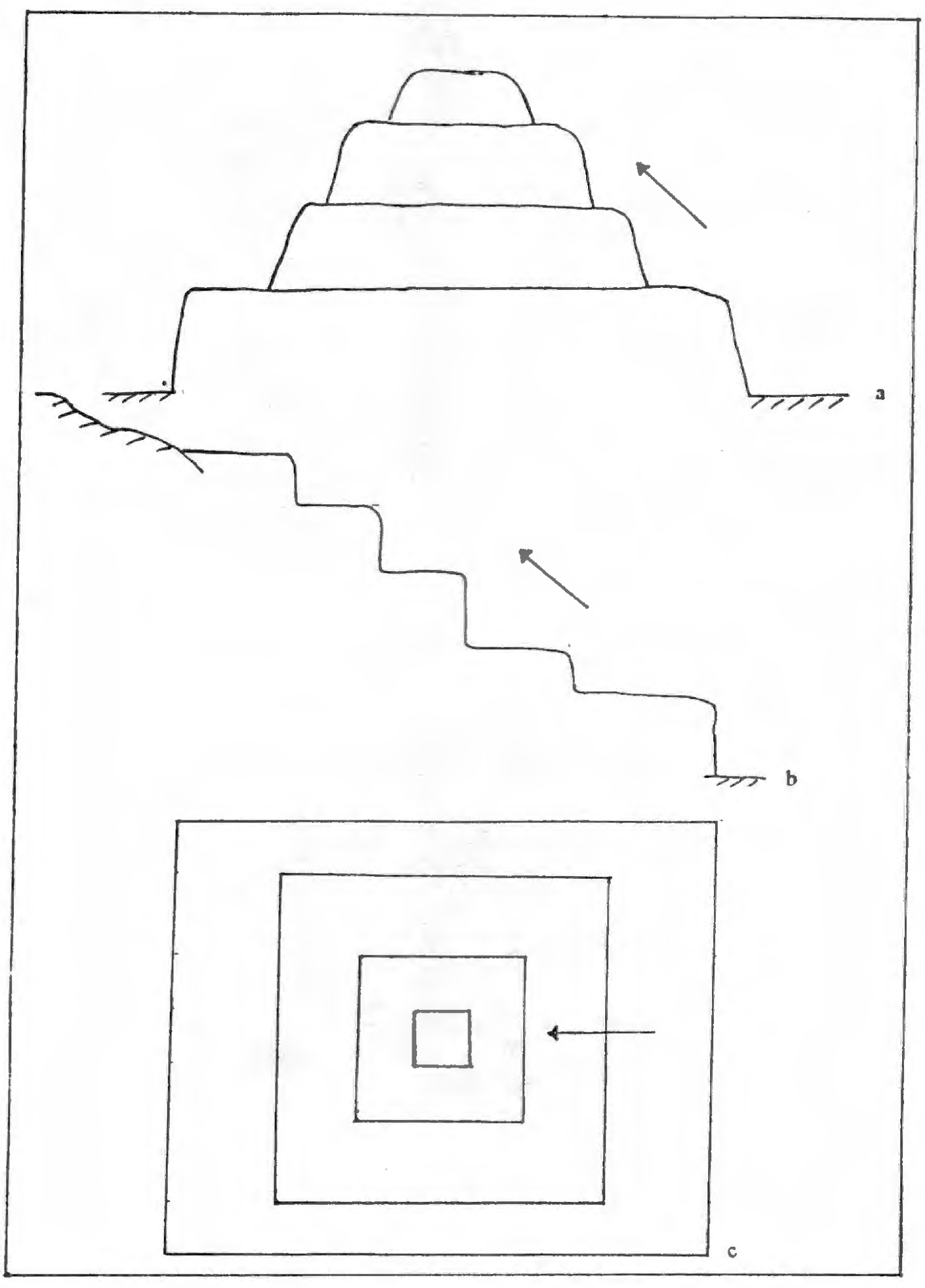

Gambar 1. Punden Berundak

a \& c. Memusat ke tengah (a. tampak samping dan c. tampak atas)

b. Memusat ke belakang (tampak samping) 


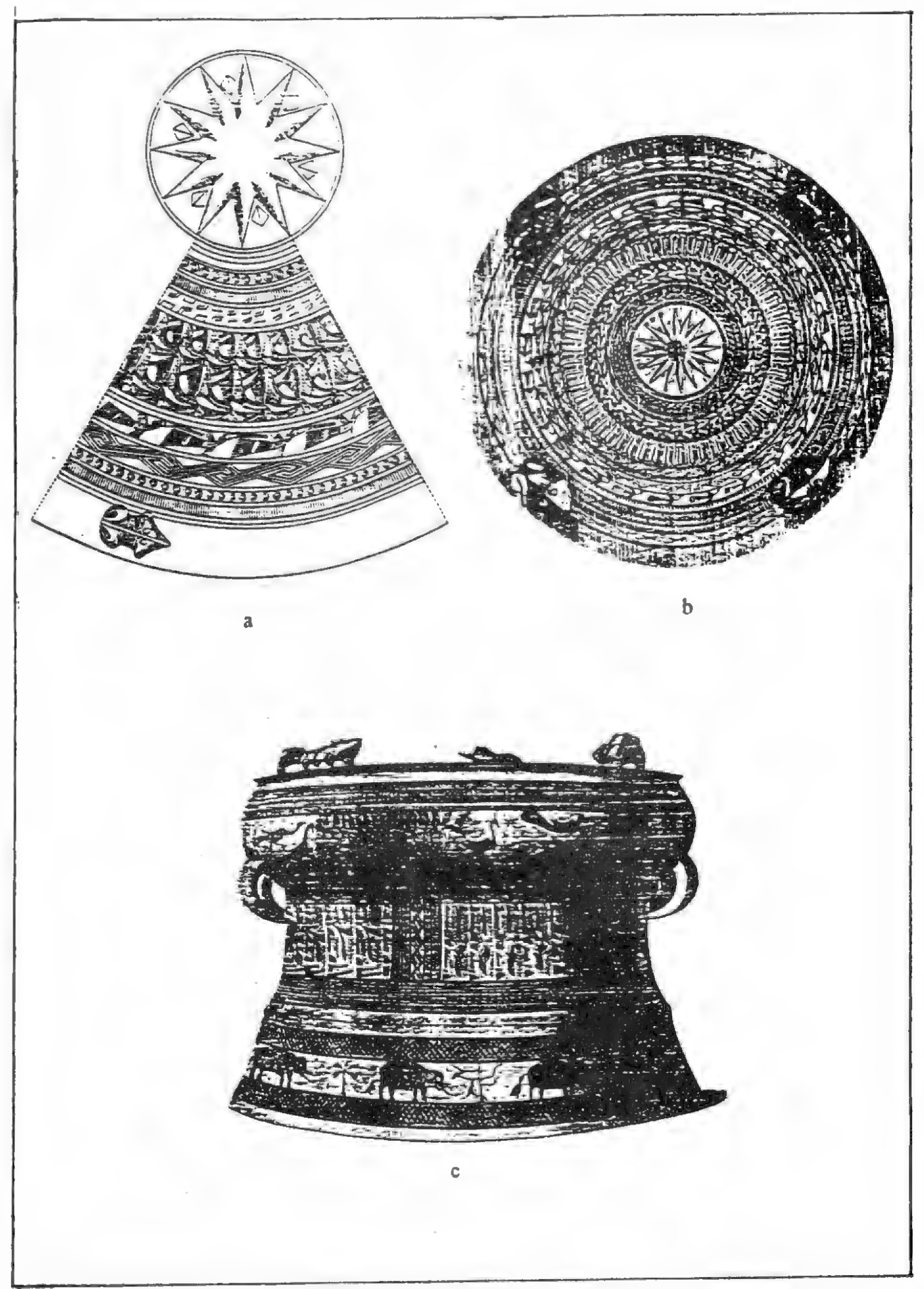

Gambar 2. Nekara Perunggu

a. Nekara Roti (pola hias bagian tympanon)

b \& c. Nekara Salayar (b. pola hias bag. Tympanon; c. pola hias bag. tubuh) 